\title{
The Relationship Between Economic Development and the Education of Rural Doctors
}

\author{
Jinguo Wang \\ Department of Urology \\ The First Hospital of Jilin University \\ Changchun, China \\ wangjinguolily@163.com
}

\author{
Corresponding author: $\mathrm{Na}$ Wang \\ Department of Anesthesiology \\ The First Hospital of Jilin University \\ Changchun, China \\ wangna080613@163.com
}

\begin{abstract}
The effect of economic development on education of rural doctors is analyzed in this paper. According to the literature report, we investigate how the county health bureau and township health hospital implement the medicine education to doctors and how the rural doctors participate in the medical education from different economic levels. The level of economic development in the countryside doesn't obviously vary with the education training funds of county-level health bureau and the economic income level of rural doctors. Economic conditions play an important role in promoting the development of rural doctors' education, but it is not the only determinant factor.
\end{abstract}

Keywords-Economy; Development; Education; Rural Doctors; Relationship

\section{INTRODUCTION}

Economics and education are the two foundations of modern social development. Research on the relationship between them is the focus of education economics research. As the after-work education level, education is more closely related to economic growth, especially since the expansion of education. Previous studies have used static analysis to explore the correlation between the two. In contrast to previous studies, this paper considers that the development of education and economic growth are two interactive systems, and the review research can find the real relationship between them more than static studies [1].

The incongruity between education and rural economic growth in rural China has adversely affected economic development. On the base of the division of labor theory, from the rural education, the division of labor and the internal relation of the rural economy and rural education promote the system innovation of rural economic growth, for the harmonious society construction and theoretical and empirical support for the development of urban and rural education as a whole [2]. The function of education is an important mechanism for education to promote economic growth.

\section{DEFECTS OF RURAL EDUCATION}

\section{A. Lack of Structure and System}

According to the current situation, the level of the organization system, there are three problems in infrastructure, structure and function. The insufficient number of rura education institutions is the main problem. The overall education level of rural doctors is not high. Therefore, farmers can't get the rural basic conditions. The rural education structure is unreasonable, and the rural professional education is neglected, and the technical training of rural doctors is insufficient to meet the technical requirements of the medical treatment in the countryside [3]. There are problems in the function positioning of the rural education institution, which is not enough to cultivate the open consciousness and professional consciousness. What's more, the innovation ability of the doctors is also lacking.

According to the operational system, there are three problems. There are lack of dynamic mechanism, unscientific incentive mechanism and unreasonable constraint mechanism. In the financing system, the rural education investment is insufficient. The countryside elementary education financing system is not reasonable. The outflow of university talents is caused by high charge and financial problems, which can be released by the division of labor education function and the rural economy growth [4]

\section{B. Maintaining the Integrity of Rules and Regulations}

To service the police of agriculture, the market-oriented, competitive, different, coordinated and systematic develop rural education to promote rural economic growth mechanism, incentive mechanism and constraint mechanism [5]. We should strengthen the formulation and improvement of the laws and regulations in the rural basic education, so as to create a good atmosphere of respecting teachers in the whole society and strengthen the self-discipline of education institutions.

To support, encourage and guide the rural professional education institutions to strengthen their own competitive consciousness and innovation consciousness, and establish the performance assessment mode based on the employment flow of vocational school graduates. The central government and society should strengthen the supervision and management of the education institutions of rural hospitals. Rural governments 
establish a coordination mechanism to build the rural grassroots clinics, rural education institutions, rural industry organizations and relevant scientific research institutes of socialization service system of rural education. They also should establish all kinds of related subject, rural dynamic mechanism of social service system, resource allocation mechanism, service mechanism and evaluation mechanism. We will continue to promote the construction of rural informatization projects and create conditions for the thorough settlement of the education requirements for rural residents.

\section{MAJOR PROBLEMS NEEDED TO BE ADDRESSED}

With the expansion of medical education, the important contents of the rural health work of rural doctor education also got better developed. The quality of rural doctors and health service are continuously improved. However, there has always been an uneven development of rural doctors' education [6]. This paper aims to explore the development of medical education in rural doctors from the perspective of different economic development.

Cheating in exams is more serious and harmful, and it is considered that cheating in exams is a sign of low morality. They are subjective against cheating, but a certain proportion of students are lack of awareness of the danger and severity of cheating in the exam, even moral distortions. Medical work is too busy, so they have no time to review. Examination questions are too difficult. Influence of the bad social ethos, the low quality of examinees is also the main factors influencing the students cheat. We suggest that the related department attaches great importance to the problem of cheating in the exam, take measures to strengthen ethics and integrity education, aiming at key factors and the key problem to strengthen management, improve the doctor degree in the phenomenon of cheating in the exam.

\section{A. Uneven Quality of Rural Doctors}

How to eliminate and reduce differences between regions needs to be studied. The comprehensive and coordinated development of rural doctors' education is needed. It is very important develop the education planning and regulations to implement the training of education planning and regulations reasonably.

On this basis, relevant knowledge and technical training can be carried out in combination with local practical and rural doctors' characteristics, so as to promote the all-round development of rural doctors' quality [7]. In order to make rural doctors fully understand the basic medical and public health service responsibilities, unilateral pursuit of the development of a professional technical capability should be avoided.

According to the results of the previous study, the proportion of rural doctors who want to accept advanced education is still lower, indicating that some rural doctors have no enthusiasm for the education. The reason for the problem is that the education model has close relationship with education cost.

Although rural doctors in the education and training have the good development level, they still relatively perform well in the practical applications. They get the knowledge mainly from the centralized lecture or seminar, other forms of training. The special skill training to the regular high-level units or professional theory study is a little. That is against the development of higher education [8].

In addition, some rural doctors don't think they need requirements to participate in education training. In addition to the individual cognitive reason, without management, training becomes a mere formality, or simple repetition. It ignores the actual effect from the actual simple notice to complete relevant indicators.

\section{B. Impact of Economic Development}

The impact of economic development on the education of rural doctors is reflected in the individual doctor level of county, township and village [9]. County economic development level and training level, for the county health education training and training hours and person-time financial income and in towns and townships, villages and towns training funding and training people, the economic income of rural doctors have correlation with record of formal schooling education, etc.

The training funds of township institutes of health, the cumulative number of training courses and the education level and demand of rural doctors are different from different economic levels. Therefore, the impact of the economic situation on rural doctors' education is mainly reflected in the personal level of rural doctors [10].

Although there is no statistical significance in the education training funds and the training of township health, the indicators still show the trend of changing with the economic level.

\section{The Role of Economic Development}

Education training is an essential element in the implementation of education of rural doctors. The good economic development level is the important support and guarantee for the normal development of village doctor education.

According to the literature, the economic development level has an objective effect on rural doctor education. Economic development level and village doctor education implementation results suggest that the influence of the township financial revenue is closely related with townships training funds invest. The economic level is important to rural doctors' on-the-job training [11].

Education training is an essential element in the implementation of education of rural doctors. The good economic development level is the important support and guarantee for the normal development of village doctor education.

According to the survey, the economic development level has an objective effect on rural doctor education. Economic development level on the implementation results of village doctor education. The influence of township financial revenue on training funds is obvious, and the economic level is important to rural doctors' on-the-job training. 


\section{EDUCATION FAIRNESS}

Education as a kind of public products and the national legislation of every citizen' rights should be enjoyed by everyone. Equality is necessary for education which is important for individual existence and development and the foundation of the national development and national rejuvenation.

This determines that the fair appeal of education reform is different from different levels of economics, politics or other aspects. In terms of value, education fairness is a kind of education ideal, which is to achieve the social justice through the fairness of education [12].

\section{A. Eeducation Equity}

From a political view, education equity is to adjust the imbalance between supply and demand in the present situation. It includes not only economic sense, rational allocation and effective use of social total resources in education, but also includes the philosophy and sense of law opportunities and fair distribution of education rights.

Historically, the education justice has been a changing historical category with the times. At the time of the unpopularity of education, education's fair meaning is to guarantee the rights of more people to be exposed to education. After the popularization of education, education is fair to ensure that all citizens are basically exposed to education quality.

When the political, economic and cultural levels of the society develop to a certain height, education is equal to the requirement to provide quality education for major people. Education's fair and unique connotation is derived from rich and updated theoretical support, which mainly includes education equity theory, education human rights theory and education modernization theory.

\section{B. The Government Intervention}

In the education policy, the government policy includes the vertical programs state and local government education reforms, the horizontal education reform. The ministry of education constantly increases investment in education resources and regulation.

According to the policy, governments at all levels promote the education reform measures in accordance with the law and timely feedback, so as to realize effective benign interactive education reform and policy makers [13].

For this reason, the experience of education reform can provide reasonable enlightenment for balanced development to accurately grasp the fairness of education and adhere to the government's teaching and democratic decision-making in accordance with law.

We will continue to guarantee the financial input of education and improve the fair and adequate payment system. The system of education compensation for vulnerable groups should be established for reasonable allocation of teacher resources. Education development goals and standards should be established, education supervision and accountability should be strengthened.

\section{Application of Market Principles}

It is the essence of the value of life to define the whole standard value, and the individual standard value can only be realized in the process of creating value for the society. The combination of the value orientation and the market economic value concept can establish the life value with the whole standard as the core.

Only the correct value orientation of market economy can provide healthy growth with the medical professional spirit, which is not only a problem in medical field, but also a social problem. As long as the theoretical researchers and practitioners work together to rebuild the trust between doctors and patients, it is possible to make medical professionalism deeply popular [14]. The implementation of medical professionalism also requires a long process of exploration.

\section{SUMMARY}

The main contents of rural doctors' education include education funds and organizational implementation. Its effectiveness is influenced by many factors. The survey data show that the level of local economic development, education training and rural doctors' personal economic conditions for rural doctors education implementation and the rural doctors.

It is necessary to strengthen the rural infrastructure construction and reduce the transaction cost of rural economy, so as to facilitate the realization of the function of education division. To implement and coordinate of the development of rural education, it realizes the education development and synchronous trading environment to increase the level of specialization to promote division of majors, through education and superposition effect of economic terms.

Township financial revenue has a significant influence on the training funds of the health institutes. Education training will be implemented by its health bureau and education training funds of the county health bureau are influenced by the levels of economic development. The two indicators of the training funds and the accumulative training in the township hospitals are statistically significant. Rural doctors with different income levels have significant differences in medical education.

The impact of personal income of rural doctors on the education of rural doctors is not identical. It also has not significant effect on the other indicators. It has no obvious correlation between the economic income and education participation rate of rural doctors in the county health bureau and between towns. There is low proportion of the number of rural doctors who are taking formal schooling education. Although there will still be rural doctors failed to get regular medical degree, but the demand for education of technical secondary school degree and technical secondary school does not increase with the economic income level. From this point of view, with the economic development, financial investment of education to promote village doctor education is quite important, but not the only determining factor. 


\section{REFERENCES}

[1] Scott Franklin Abernathy. No Child Left Behind and the Public Schools Journal of Women s Health. 2007.

[2] L Dean Webb. The History of American Education:AGreat American Experiment. Journal of Women s Health. 2006.

[3] The U.S Department of Education.America 2000: An Education Strategy. 1991.

[4] Common Core State Standards Initiative. Common Core State Standards for Mathematics. 2010.

[5] Hegel G.W.F, Trans T.M.Knox. Philosophy of Right. 1962.

[6] Lau L. J., D. T Jamison, S. C. Liu, S Rivkin. Education and Economic Growth:Some Cross-sectionalEvidence from Brazil. Journal of Development Economics. 1993.

[7] Wen M. An Analytical Framework of Consumer-Producers Economies of Specialisation and Transaction Costs. Increasing Returns and Economic, Analysis. 1998.
[8] Yang X. Economics: New Classical versus Neoclassical Frameworks. 2001.

[9] Schultz T.W. Education and Economic Growth. 1961.

[10] Allyn Young. Increasing Returns and Economic Progress. The Economic Journal. 1928.

[11] Lucas Robert E. On the Mechanics of Economic Development. Journal of Monetary Economics. 1988.

[12] Ravitch Diane. The Troubled Crusade: American Education,1945-1980. Journal of Women's Health. 1983

[13] John Gray. Liberalism. Journal of Women's Health . 1986.

[14] Juanita Cruz Martinez. Embracing Diversity, Seeking Social Justice, and Achieving Educational Equity through Multiculturalism. Multicultural Education. 2005. 